\title{
Physical Chemical Properties of Fermented and Roasted Rambutan Seed Fat (RSF) as A Potential Source of Cocoa Butter Replacer
}

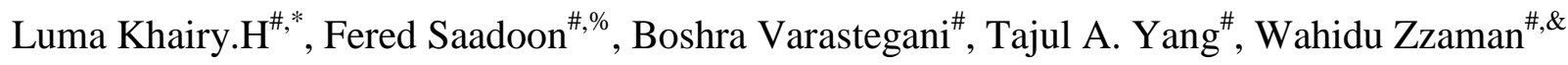 \\ ${ }^{\#}$ Food Technology, School of Industrial Technology, University Sains Malaysia, Minden 11800 Pulau Pinang Malaysia \\ E-mail: taris@usm.my \\ * Department of Food Science, School of Agriculture, University of Baghdad, Baghdad-Iraq \\ Email:luma_khairy@yahoo.com \\ ${ }^{\%}$ Department of Quality control, General Company for Grain Processing, Ministry of trade, Baghdad, Iraq \\ E-mail:feredabuaimen@yahoo.com \\ ${ }^{\&}$ Department of Food Engineering and Tea Technology, Shahjalal University of Science and Technology, Sylhet-3114, Bangladesh \\ Corresponding author Email: wahidaft@yahoo.com
}

\begin{abstract}
Rambutan (Nephelium opossum L) is one of the most important tropical fruits that is originally found in Malaysia, Thailand, the Philippines, Vietnam, Borneo and other countries in this region. The industrial processing of this fruit produces seeds and peels as waste materials. The aim of this work was to determine the physical-chemical properties of fermented-roasted Rambutan seed fat (RSF) and its mixtures with Cocoa butter (CB) in term of viscosity, texture (hardness), thermal stability, and fatty acid composition, and free fatty acid, acid value. The mixtures M3, M4, and RSF which possess similar crystal formation showed almost similar hardness index in the range of 11.18 to 24.77. The mixtures M1 and CB exhibited higher hardness index than M2, M3, M4 and RSF in the range of $\mathbf{5 7 . 5 5}$ to $\mathbf{6 3 . 8 5}$. The results showed that a low viscosity was observed in the mixture CB and M1 with increasing the temperatures at 35, 40 and $50 \mathrm{oC}$ whereas, a high viscosity was observed in the other mixture such as M3, M4, and RSF with increasing the temperature, respectively. The result found that the major fatty acid composition was present in CB $(100 \% \mathrm{CB}+0 \% \mathrm{RSF})$ and $\mathrm{M1}(\mathbf{8 0} \% \mathrm{CB}+20 \% \mathrm{RSF})$, such as palmitic, stearic and oleic acid, respectively. The results showed no significant differences $(P>0.05)$ in FFA among CB $(2.72 \pm 0.65 \%)$, M1 $(3.01 \pm 0.32 \%)$ and M2 $(3.47 \pm 0.16 \%)$. At the same time, the results of A.V showed significant differences $(P<0.05)$ among $C B(4.68 \pm 1.29)$, M1 $(5.98 \pm 0.64)$ and $M 2(6.92 \pm 0.33) \mathrm{mgKOH} / \mathrm{g}$, respectively, but M1 value was very close to $\mathrm{CB}$ value. The results exhibited that CB and M1 had a lower viscosity than M2, M3, M4 and RSF with increasing temperature. From these results, it was found that it is possible to utilize rambutan seed fat as a cocoa butter replacer in a suitable ratio depending on the final products.
\end{abstract}

Keywords — rambutan seed; cocoa butter; texture; thermal stability; fatty acid composition

\section{INTRODUCTION}

Fats are used as main ingredients in food, cosmetic, and pharmaceutical products [1]. The crystallization of fats has industrial applications when it is controlled; end products such as chocolate, margarine, and whipped cream can be obtained; the crystallization phenomenon of fats can be used to isolate fats from natural resources [2]. Cocoa butter (CB) is one of the natural fats, obtained from cocoa seeds (Theobroma cacao); it is typically used as a major component of chocolate and other confectionery products because of its physical and chemical properties [3]. $\mathrm{CB}$ is solid at room temperature (below $25^{\circ} \mathrm{C}$ ) and liquid at body temperature $\left(\sim 37{ }^{\circ} \mathrm{C}\right)$; it consists mostly of palmitic $\left(\mathrm{C}_{16}\right)$, stearic $\left(\mathrm{C}_{18: 0}\right)$, and oleic acids. Virtually, all oleic acids are esterified in the central position of all glycerol molecules $(\mathrm{Sn}-2)$, whereas saturated fatty acids are typically located in $(\mathrm{Sn}-1,3)$ positions. The composition and allocation of fatty acids lead to a symmetrical triglyceride composition of $\mathrm{CB}$ that is rich in 1,3-dipalmitoyl1-2-oleoyl-glycerol (pop) and 1-palmitoyl-3-stearoyl-2-oleoyl-glycerol (POS) [4]. This triglyceride composition of $\mathrm{CB}$ is generally responsible for its diverse crystalline polymorphic forms, while fatty acid compositions are responsible for fat solidification in its liquid state [5]. $\mathrm{CB}$ is known to be more expensive than other vegetable fats because of its specific characteristics 
and it is cultivated in only a few countries [6]. Therefore, the food industry is keen to find other sources of fats as alternatives to $\mathrm{CB}$ in producing chocolates for various reasons, including economic [7]. $\mathrm{CB}$ alternatives are defined as non-lauric fats that can replace $\mathrm{CB}$ either partially or completely in chocolate or other food products. Lipp and Anklam [8] previously mentioned that the utilization of natural or processed lipids as cocoa butter alternative can be decided using its compositional data (fatty acid composition and triacylglycerol conformation) and thermal characteristics such as crystallization and melting characteristic. This work was intended to determine the physical properties of fermented-roasted RSF and its mixtures with CB in viscosity, texture (hardness), thermal stability, fatty acid composition, free fatty acid, acid value to compare these mixtures with $\mathrm{CB}$ and to determine the mixture which was more similar to cocoa butter properties.

\section{MATERIALS AND METHODS}

\section{A. Materials}

CB was purchased from an Indonesian coffee company and the Cocoa Research Institute, Jember, East Java, Indonesia. Meanwhile, raw rambutan (Nepheliumlappaceum L.) seeds were supplied by a rambutan canning industry in Sungai Petani, Kedah, Malaysia.

\section{B. Fermentation and Roasting of Rambutan Seeds}

The fermentation process was performed on rambutan seeds, which were still covered by small amounts of rambutan pulp. The rambutan seeds were transferred into plastic baskets $(625 \mathrm{~mm} \times 425 \mathrm{~mm} \times 294 \mathrm{~mm})$, which were previously lined with banana leaves. After filling in the baskets with raw rambutan seeds, the baskets were covered with banana leaves for 6 days, with mixing every 3 days. On the $6^{\text {th }}$ day of fermentation, the banana leaves cover was opened and the rambutan seeds inside the fermentation container were stirred with a wood spatula. After the fermentation time was sufficient, the dried rambutan seeds were roasted at $150{ }^{\circ} \mathrm{C}$ for 30 minutes by oven-drying (AFOS Mini Kiln, Hull, England). After roasting, the samples were cooled at room temperature and stored until the screw-pressing process for RSF production [9].

\section{RSF Extraction}

RSF extraction was performed using a KOMET screw oil expeller DD 85 IG (IBG MonfortsOekotec GmbH \& Co. KG, Ger-many). Dried rambutan seeds were dehusked and heated at $60{ }^{\circ} \mathrm{C}$ for 30 minutes by oven-drying (AFOS Mini Kiln, Hull, England). The screw-pressing process produced RSF, which was a viscous mixture of rambutan seed powder and RSF. The separation of RSF from rambutan seed butter was achieved through filtration under a heated condition $\left(60^{\circ} \mathrm{C}\right)$. Afterward, the collected RSF was transferred into inertscrew-cap bottles [9].

\section{Preparation of RSF and Cocoa Butter Mixtures}

Mixtures of rambutan seed fat and cocoa butter were prepared following proportions as mentioned in Table 3.1. The levels were in the range of $0 \%$ to $100 \%$ with the total mixture was $100 \%(\mathrm{CB}+\mathrm{RSF}=1)$. The mixing process was carried out by adding predetermined proportions (w/w) of cocoa butter and rambutan seed fat.

TABLE I

PROPORTION OF THE RSF AND COCOA BUTTER

\begin{tabular}{|l|l|l|}
\hline Mixtures of CB \& RSF & CB\% $^{\text {a }}$ & RSF \% $^{\mathbf{b}}$ \\
\hline Mixture 1 (CB) & 100 & 0 \\
\hline Mixture 2 (M1) & 80 & 20 \\
\hline Mixture 3 (M2) & 60 & 40 \\
\hline Mixture 4 (M3) & 40 & 60 \\
\hline Mixture 5 (M4) & 20 & 80 \\
\hline Mixture 6 (RSF) & 0 & 100 \\
\hline
\end{tabular}
fat

$\mathrm{CB}$ was incorporated into RSF in six proportions, namely, 100/0, 80/20, 60/40, 40/60, 20/80, and 0/100 (w/w) CB to RSF, as CB, M1, M2, M3, M4 and RSF respectively. Then, the mixtures were melted in the oven (AFOS Mini Kiln, Hull, England) at $60{ }^{\circ} \mathrm{C}$ for $15-20$ minutes. The melted mixtures were then homogenized using a vortex and transferred into inert-screw-cap bottles and then stored at $-4{ }^{\circ} \mathrm{C}$ until they were used for analysis.

\section{E. Texture Properties (Hardness Index)}

Texture properties analysis was carried out using TA.XT Plus texture analyzer (Stable Micro System, Ltd., UK) following the method of Lannes et al. [10]. Cone probe was utilized during this analysis and was set to penetrate the samples with a constant speed of $2.0 \mathrm{~mm} / \mathrm{s}$ for $10.0 \mathrm{~mm}$. The analysis was performed at $20^{\circ} \mathrm{C}$. The result of the analysis was expressed as hardness diagram.

\section{F. Thermal Stability Analysis}

Thermal stability of RSF and CB mixture samples were analyzed by means of thermal gravimetric analysis (TGA) in nitrogen atmospheres employed TGA 4000 equipped with C6 cooler (Perkin Elmer, Waltham, Massachusetts, USA). The nitrogen flow rate was set at $50 \mathrm{ml} / \mathrm{min}$ at a heating rate of $20^{\circ} \mathrm{C} / \mathrm{min}$. Mass changes were recorded between 25 until $700{ }^{\circ} \mathrm{C}$.

\section{G. Viscosity Measurement}

The viscosity was measured by use Viscometer Model (SV-10 Japan). It was taken $45 \mathrm{ml}$ of the sample and transfers to Viscometer vial and then read the number of the viscosity. Each value was taken triplicate at temperature 25 ${ }^{\circ} \mathrm{C}$.

\section{H. Fatty Acid Composition}

Fatty acid methyl ester (FAME) was prepared according to the method of Mondello et al. [11]. Melted samples (0.05 g) were transesterified in a Pyrex tube by using $2 \mathrm{ml}$ of borontrifluoride-methanol (20:80) reagent then heated for 30 min at $100^{\circ} \mathrm{C}$ in water bath. The heated solution was cooled to room temperature. After cooling down, $2 \mathrm{ml}$ of n-hexane and $8 \mathrm{ml}$ of distilled water were added to the mixture, which was then mixed manually for $1 \mathrm{~min}$ and centrifuged at 3500 rpm for 2 minutes. Approximately $1 \mathrm{ml}$ of the upper $\mathrm{n}$ hexane layer was transferred to a $1.5 \mathrm{ml}$ glass insert for $2 \mathrm{ml}$ vials after diluting the extracted hexane to obtain a suitable chromatographic response. Gas Chromatography (GC) 
analysis was done using GC 2010 plus- FID (flame ionization detector) (Shimadzu Corp., Nagakyo-ku, Kyoto, Japan) equipped with SGE BPX70 (90\% Cyanopropylphenyl Polisiloxane, $0.32 \mathrm{~mm}$ ID $\times 0.25 \mu \mathrm{m} \times 30 \mathrm{~m}$ ) column $(\mathrm{SGE}$ Analytical Science Pty Ltd, Victoria, Australia). The condition of GC during the analysis was set as follows: The injection port was set using split mode (split ratio $=1: 10$ ) at temperature $250^{\circ} \mathrm{C}$ employed Helium (He) as carrier gas [11]. The column temperature was set at $70 \mathrm{oC}$ maintained for 1 min, then increasing to $150^{\circ} \mathrm{C}$ at $20^{\circ} \mathrm{C} / \mathrm{min} \mathrm{ramp}$ and then increasing to $250^{\circ} \mathrm{C}$ at $10^{\circ} \mathrm{C} / \mathrm{min}$ ramp. The final temperature was maintained for $15 \mathrm{~min}$. Fatty acids were grouped as follows: saturated (SFA), mono (MUNA) and poly (PUFA) fatty acids.

\section{Analysis of Free Fatty Acid (FFA) and Acid Value (A.V)}

The FFA was determined according to the method [12]. The first step was prepared $50 \mathrm{ml}$ of alcohol by added in 2 $\mathrm{ml}$ phenolphthalein solution and $0.1 \mathrm{M}$ sodium hydroxide $(\mathrm{NaOH})$ and produced a faint permanent pink. 7.05 grams of melted fat sample were weighed into $250 \mathrm{ml}$ conical flask and mixed with prepared neutralized $50 \mathrm{ml}$ of alcohol at first step. Then, the mixture was titrated with $0.25 \mathrm{M}$ sodium hydroxide $(\mathrm{NaOH})$ with a vigorous shaking until a permanent faint pink developed. The volume of 0.25 sodium hydroxide $(\mathrm{NaOH})$ used in the titration steps was taken as final read. The free fatty acid of the samples was expressed as a percentage of oleic acid that was $\mathrm{ml}$ of $0.25 \mathrm{M}$ sodium hydroxide $(\mathrm{NaOH})$ used in the titration of the sample. All samples were measured in triplicate. The acid value of RSF and its mixture with $\mathrm{CB}$ samples are correlated with free fatty acid determination. FFA may also be expressed in terms of acid value. The acid value of the samples was calculated by the equation below:

$$
\text { A.V }=\text { percentage of fatty acid (as oleic) } \times 1.99
$$

\section{J. Statistical Analysis}

Samples were carried out in triplicate and the data analysis was using (ANOVA) followed by post hoc analysis, Duncan multiple comparison analysis and all the data were analysis using SPSS (Statistical Package for Social Science) software version 20 (IBM Corporation, Armonk, New York 10504-1722 United State). The statistical analysis was performed at 0.05 significant levels.

\section{RESULTS AND DISCUSSION}

\section{A. Texture Properties (Hardness Index)}

The differences in crystal formation of the mixtures greatly affected their texture properties. As shown in Fig. 1, the mixtures M3, M4 and RSF which possess similar crystal formation showed almost similar hardness index in the range of 11.18 to 24.77. The mixtures M1 and CB exhibited higher hardness index than M2, M3, M4 and RSF in the range of 57.55 to 63.85 . These results were agreed with Febrianto [9], he found the hardness of the mixtures (RSF: CB) were lower ranged from 21.32 to 27.91 compared to 56.34 in $\mathrm{CB}$. However, he showed a slightly different characteristic of hardness in the mixture $(90 \% \mathrm{CB} / 10 \% \mathrm{RSF})$ compared to cocoa butter. Size and the distribution of crystal formation may be the responsible factor for the difference between M2, M3, M4 and RSF mixtures with M1 and CB. Smaller and well-distributed crystal formation provides a higher hardness index, whereas bigger crystal formation resulted otherwise.

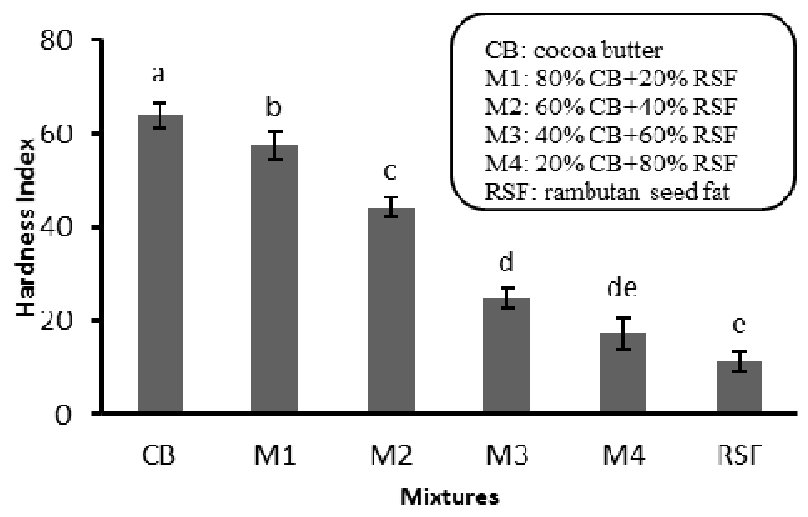

Fig. 1 Changes in the hardness index of RSF and its mixtures with CB

\section{B. Thermal Stability}

The result of thermal stability analyses carried out on RSF and its mixture with $\mathrm{CB}$ are shown in Table 2. The decomposition temperature of M1 was more similar to $\mathrm{CB}$, it was observed in onset 344.39 and 394.59, mass loss rate 1.38 and 0.79 , and the final decomposition temperature 521.14 and 616.06 of the M1 and CB, respectively. This result indicated that $\mathrm{CB}$ and $\mathrm{M} 1$ were more resistant from thermal decomposition than other mixtures. However, the other mixtures showed different results; decomposition of M2, M3, M4, and RSF started at 308.62, 306.75, 302.60 and 291.91 , and ended at a lower temperature ranged around $489.89,487.52,485.85$ and 482.83 than that of the CB and M1 with the highest mass loss recorded at around 1.25 to $1.12 \% /{ }^{\circ} \mathrm{C}$, respectively.

Previously, Lawler and Dimick [13] showed that cocoa butter possessed the unique characteristic of polymorphism. As mentioned in section 3.3.3; CB and M1 crystallized as $\beta$ form crystal, The $\beta$ crystal formation possesses hard, but the brittle texture of cocoa butter which is usually used for storage and product development. This formation of the crystal is also desirable due to its unique snap characteristic and fast melting in the mouth feature. Therefore, CB and M1 were more resistant from thermal decomposition than the mixture M2, M3, M4 and RSF, which crystallized in $\beta$ and $\beta^{\prime}$ form crystal. Nonetheless, similar to the thermal behavior discussed in section 3.3.2; different thermal stability of RSF compared to the $\mathrm{CB}$ may be also contributed by the TAG composition.

\section{Viscosity Measurement}

The changes in physical properties of rambutan seed fat and its mixture with cocoa butter during the roasting process are considered a reliable guide to follow up the changes in viscosity affected by different temperature. 
TABLE II

TGA DEGRADATION POINT OF RSF AND ITS MiXTURE WITH CB

\begin{tabular}{|c|c|c|l|r|l|l|}
\hline \multirow{2}{*}{ Sample } & \multicolumn{6}{|c|}{ Degradation point $\left({ }^{\circ} \mathbf{C}\right)$} \\
\cline { 2 - 8 } & Onset & Max 1 & $\begin{array}{l}\text { Mass } \\
\text { loss } \\
\text { rate 1 } \\
\left(\% /{ }^{\circ} \mathbf{C}\right)\end{array}$ & Max 2 & $\begin{array}{l}\text { Mass } \\
\text { loss } \\
\text { rate 2 } \\
\left(\% /{ }^{\circ} \mathbf{C}\right)\end{array}$ & Offset \\
\hline CB & 394.59 & 431.69 & 0.22 & 522.12 & 0.79 & 616.06 \\
\hline M1 & 344.39 & 391.66 & 0.81 & 482.66 & 1.38 & 521.14 \\
\hline M2 & 308.62 & 338.53 & 0.87 & 432.92 & 1.25 & 489.89 \\
\hline M3 & 306.75 & 311.66 & 0.64 & 430.68 & 0.98 & 487.52 \\
\hline M4 & 302.60 & 307.96 & 0.71 & 429.53 & 1.12 & 485.85 \\
\hline RSF & 291.91 & 306.39 & 0.52 & 425.01 & 1.12 & 482.83 \\
\hline
\end{tabular}

The results of viscosity measurement are given in Fig. 2 . The results showed that a low viscosity was observed in the mixture $\mathrm{CB}$ and $\mathrm{M} 1$ with increasing the temperatures at 35 , 40 and $50 \mathrm{oC}$. whereas, a high viscosity was observed in the other mixture such as M3, M4, and RSF with increasing the temperature, respectively. 4

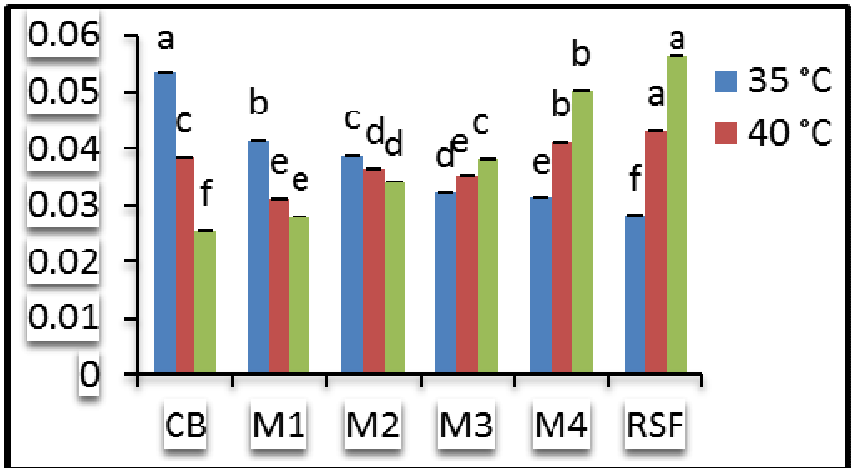

Fig. 2 Changes in viscosity of RSF and its mixtures with $\mathrm{CB}$ at different temperature

These results correspond with Zzaman et al. [14], he suggested that mixture proportion up to $30 \%$ rambutan seed fat had a higher viscosity than cocoa butter. Accordingly, cocoa butter had a lower viscosity than rambutan seed fat, which can be explained by type and long chain structure of fatty acid and triacylglycerol composition [15]. According to Lannes et al. [16] noted that characterized by the melting of fat crystals is defined as the level of fat in a reticular structure which are typically structured in the form of $\beta$ ' that conducted lead to higher viscosity more than $\beta$ form structure that given their smaller size, higher surface area and potentially increased interfacial viscosity in emulsions.

\section{Fatty Acid Composition}

Cocoa butter contains many different lipids or fats. According to Lannes and Gioielli [17] described that primary triacylglycerols that combined with the cocoa butter including; palmitic, stearic, and oleic fatty acids. Saturated and unsaturated acids are obtained from many fats and lipids combination of the fatty acids, which half of them are heterogeneous. The fatty acid composition of all mixtures was significantly different $(\mathrm{p}<0.05)$ from one another as shown in Table 3.
TABLE III

FATTy ACID COMPOSITION (\% AREA) IN THE CB AND RSF MiXTURE

\begin{tabular}{|l|l|l|l|l|}
\hline $\begin{array}{l}\text { Fatty } \\
\text { acid }\end{array}$ & M1 & M2 & M3 & M4 \\
\hline C8:0 & $1.13 \pm 0.02^{\mathrm{e}}$ & $1.27 \pm 0.01^{\mathrm{d}}$ & $1.41 \pm 0.01^{\mathrm{c}}$ & $1.55 \pm 0.01^{\mathrm{b}}$ \\
\hline C11:0 & $0.15 \pm 0.01^{\mathrm{e}}$ & $0.30 \pm 0.01^{\mathrm{d}}$ & $0.46 \pm 0.01^{\mathrm{c}}$ & $0.61 \pm 0.01^{\mathrm{b}}$ \\
\hline C12:0 & $15.69 \pm 0.01^{\mathrm{b}}$ & $12.38 \pm 0.01^{\mathrm{c}}$ & $9.08 \pm 0.01^{\mathrm{d}}$ & $5.77 \pm 0.01^{\mathrm{e}}$ \\
\hline C13:0 & $0.88 \pm 0.01^{\mathrm{e}}$ & $1,76 \pm 0.01^{\mathrm{d}}$ & $2.65 \pm 0.01^{\mathrm{c}}$ & $3.53 \pm 0.01^{\mathrm{b}}$ \\
\hline C14:0 & $0.63 \pm 0.01^{\mathrm{e}}$ & $1.25 \pm 0.02^{\mathrm{d}}$ & $1.87 \pm 0.01^{\mathrm{c}}$ & $2.51 \pm 0.01^{\mathrm{b}}$ \\
\hline C15:0 & $0.82 \pm 0.01^{\mathrm{e}}$ & $1.65 \pm 0.01^{\mathrm{d}}$ & $2.47 \pm 0.01^{\mathrm{c}}$ & $3.31 \pm 0.01^{\mathrm{b}}$ \\
\hline C16:0 & $22.14 \pm 0.01^{\mathrm{b}}$ & $18.55 \pm 0.01^{\mathrm{c}}$ & $14.97 \pm 0.01^{\mathrm{d}}$ & $11.38 \pm 0.01^{\mathrm{e}}$ \\
\hline C16:1 & $2.65 \pm 0.01^{\mathrm{e}}$ & $5.31 \pm 0.01^{\mathrm{d}}$ & $7.94 \pm 0.01^{\mathrm{c}}$ & $10.59 \pm 0.01^{\mathrm{b}}$ \\
\hline C18:0 & $18.05 \pm 0.01^{\mathrm{b}}$ & $15.56 \pm 0.01^{\mathrm{c}}$ & $13.08 \pm 0.01^{\mathrm{d}}$ & $10.57 \pm 0.02^{\mathrm{e}}$ \\
\hline $\begin{array}{l}\text { C18:1 } \\
\text { cis }\end{array}$ & $23.06 \pm 0.01^{\mathrm{e}}$ & $23.68 \pm 0.01^{\mathrm{d}}$ & $23.96 \pm 0.01^{\mathrm{c}}$ & $24.91 \pm 0.01^{\mathrm{b}}$ \\
\hline $\begin{array}{l}\text { C18:1 } \\
\text { trans }\end{array}$ & $0.74 \pm 0.01^{\mathrm{e}}$ & $1.47 \pm 0.01^{\mathrm{d}}$ & $2.21 \pm 0.01^{\mathrm{c}}$ & $2.94 \pm 0.01^{\mathrm{b}}$ \\
\hline $\begin{array}{l}\text { C18:2 } \\
\text { trans }\end{array}$ & $3.54 \pm 0.01^{\mathrm{b}}$ & $2.65 \pm 0.01^{\mathrm{c}}$ & $1.77 \pm 0.01^{\mathrm{d}}$ & $0.88 \pm 0.01^{\mathrm{e}}$ \\
\hline C18:3 & $2.72 \pm 0.01^{\mathrm{b}}$ & $2.54 \pm 0.01^{\mathrm{c}}$ & $2.38 \pm 0.01^{\mathrm{d}}$ & $2.21 \pm 0.01^{\mathrm{e}}$ \\
\hline C20:0 & $3.11 \pm 0.01^{\mathrm{e}}$ & $6.21 \pm 0.01^{\mathrm{d}}$ & $9.34 \pm 0.01^{\mathrm{c}}$ & $12.45 \pm 0.01^{\mathrm{b}}$ \\
\hline C20:1 & $0.65 \pm 0.01^{\mathrm{e}}$ & $1.31 \pm 0.01^{\mathrm{d}}$ & $1.94 \pm 0.01^{\mathrm{c}}$ & $2.58 \pm 0.01^{\mathrm{b}}$ \\
\hline C22:0 & $0.27 \pm 0.01^{\mathrm{e}}$ & $0.54 \pm 0.01^{\mathrm{d}}$ & $0.82 \pm 0.01^{\mathrm{c}}$ & $1.08 \pm 0.01^{\mathrm{b}}$ \\
\hline SFA & $\mathbf{6 3 . 5 2}$ & $\mathbf{6 0 . 7 8}$ & $\mathbf{5 8 . 0 9}$ & $\mathbf{5 5 . 3 4}$ \\
\hline MUFA & $\mathbf{2 6 . 4 5}$ & $\mathbf{3 0 . 4 6}$ & $\mathbf{3 4 . 1 1}$ & $\mathbf{3 8 . 4 4}$ \\
\hline PUFA & $\mathbf{6 . 2 6}$ & $\mathbf{5 . 1 9}$ & $\mathbf{4 . 1 5}$ & $\mathbf{3 . 0 9}$ \\
\hline$G C a n y s$ & \multicolumn{3}{|l}{} \\
\hline
\end{tabular}

GC analysis and expressed as \% area.

-Different superscript letter on the same row represented significantly different value $(\mathrm{p}<0.05)$.

The result found that the major fatty acid composition was present in $\mathrm{CB} \quad(100 \% \mathrm{CB}+0 \% \mathrm{RSF})$ and M1 $(80 \% \mathrm{CB}+20 \% \mathrm{RSF})$, such as palmitic, stearic and oleic acid, respectively. Whereas, two main fatty acid composition was found in RSF, such as oleic and arachidic acid, add up to almost 75\%; present also are palmitic, stearic, gondoic, palmitoleic, and behenic acids. The Palmitic acid in the RSF was present in much smaller amounts $(7.81 \%)$ than $\mathrm{CB}$ and M1 (25.72\%-22.14\%); and stearic acid in RSF also showed like a palmitic acid $(8.11 \%, 20.53 \%$ and $18.05 \%)$, respectively. The results showed that the oleic acid was found in CB and M1 (22.44\% and 23.06\%) lower than RSF $(25.53 \%)$, respectively. The lauric acid content in $\mathrm{CB}$ and M1 (18.99\% and 15.69\%) was higher than RSF (2.47\%). Moreover; Arachidic acid and other saturated fatty acid such as gondoic and behenic acid found in RSF, but those fatty acids were absent in cocoa butter, which may affect to high melting point and high viscosity of rambutan seed fat [18][19]. However, around $50 \%$ of the fatty acids in RSF is saturated, including a high percentage of arachidic acid, a fatty acid with a long chain and a relatively high melting point. This composition gives RSF characteristic physicochemical properties, thermal and phase behavior. These results agree with Zzaman et al. [14] they founded that lauric, palmitic, and stearic fatty acid in rambutan seed fat were less than cocoa butter, but oleic acid found almost the same. On the other hand, these results are quite different compared with Sirisompong et al. [20] reported that RSF is composed of $36.79 \%$ of oleic acid, $34.32 \%$ arachidic acid and $4.69 \%$ palmitic acid. However, the differences in these fatty acid proportions have also been reported previously; in which, the differences in cultivar and plantation area was suspected to be the most influencing factors. The increase of 
oleic acid in CB and RSF sample during fermentation was previously mentioned by Teng et al. [21], who found that the increase of lipase activity during fermentation using Rhizopus spp resulted the formation of oleic acid. Meanwhile, the specific microorganism such as $\mathrm{R}$. oligosporus could utilize the fatty acids in lipid body, mainly palmitic and stearic acid to support their cell wall phospholipid development, resulting in the decrease of palmitic and stearic acid in RSF. Moreover, Sudaryatiningsih and Supyani [22] mentioned that PUFA such as linoleic and linolenic acid could be generated by converting oleic acid with desaturase enzymes.

\section{E. Analysis of Free Fatty Acid (FFA) and Acid Value (A.V)}

The free fatty acid (FFA) and acid value (A.V) in cocoa butter and the mixtures with rambutan seed fat under study were in (Table 4). The results showed no significant differences $(\mathrm{P}>0.05)$ in FFA among CB $(2.72 \pm 0.65 \%)$, M1 $(3.01 \pm 0.32 \%)$ and $\mathrm{M} 2(3.47 \pm 0.16 \%)$. At the same time, the results of A.V showed significant differences $(\mathrm{P}<0.05)$ among CB (4.68 \pm 1.29$)$, M1 (5.98 \pm 0.64$)$ and M2 (6.92 \pm 0.33$)$ $\mathrm{mgKOH} / \mathrm{g}$, respectively, but M1 value was very close to $\mathrm{CB}$ value.

TABLE IIV

ANALYSIS OF FREE FATTY ACID AND ACID VALUE IN RSF

\begin{tabular}{|c|c|c|}
\hline Samples & $\begin{array}{c}\text { FFA } \\
\text { (\% oleic acid })\end{array}$ & $\begin{array}{c}\text { A.V } \\
(\mathbf{m g K O H} / \mathbf{g})\end{array}$ \\
\hline $\begin{array}{c}\text { CB } \\
(100 \% \text { CB+0\%RSF })\end{array}$ & $2.72 \pm 0.65^{\mathrm{c}}$ & $4.68 \pm 1.29^{\mathrm{d}}$ \\
\hline $\begin{array}{c}\text { M1 } \\
(80 \% \text { CB+20\%RSF })\end{array}$ & $3.01 \pm 0.32^{\mathrm{c}}$ & $5.98 \pm 0.64^{\mathrm{cd}}$ \\
\hline $\begin{array}{c}\text { M2 } \\
(60 \% \mathrm{CB}+40 \% \mathrm{RSF})\end{array}$ & $3.47 \pm 0.16^{\mathrm{c}}$ & $6.92 \pm 0.33^{\mathrm{c}}$ \\
\hline $\begin{array}{c}\text { M3 } \\
(40 \% \mathrm{CB}+60 \% \mathrm{RSF})\end{array}$ & $4.89 \pm 0.81^{\mathrm{b}}$ & $9.73 \pm 1.61^{\mathrm{b}}$ \\
\hline $\begin{array}{c}\text { M4 } \\
(20 \% \mathrm{CB}+80 \% \mathrm{RSF})\end{array}$ & $6.49 \pm 0.00^{\mathrm{a}}$ & $12.91 \pm 0.00^{\mathrm{a}}$ \\
\hline $\begin{array}{c}\text { RSF } \\
(0 \% \mathrm{CB}+100 \% \mathrm{RSF})\end{array}$ & $6.86 \pm 0.16^{\mathrm{a}}$ & $13.66 \pm 0.23^{\mathrm{a}}$ \\
\hline
\end{tabular}

-Values are mean \pm standard deviation of three replications.

-Different superscript letter on the same row represented significantly different value $(\mathrm{p}<0.05)$.

These differences in free fatty acid and acid value between $\mathrm{CB}, \mathrm{M} 1$, and M2 were small, some sample had a higher content, others had a lower content of Diacylglycerols (DAGs). Diacylglycerols are important because they retard the phase transformation from $\beta$ ' to $\beta$, this can negatively influence the cooling curve and thus be a disadvantage for the tempering of chocolates. These values are comparable to those reported by Zaidul et al. [23] who obtained free fatty acid and acid value during incorporated Palm kernel oil with cocoa butter, they found most of the blend similar values to that of cocoa butter. On the other hand, Manaf et al. [24] found that the FFA values of rambutan seed fat and cocoa butter they studied were $6.1 \pm 2.33 \%$ and $1.44 \pm 0.42 \%$, respectively. The presence of the FFA content of the cocoa butter due to the use of beans from diseased pods or hydrolysis by lipase from mold contamination. These molds can be present due to insufficient drying, extended fermentation or prolonged storage of the beans [25]. In addition, the increase in FFA and A.V values in the roasted seed fat could be contributed by hydrolysis of triacylglycerol during roasting process which produces free fatty acids with diacylglycerol. Another cause can be too quick drying of the beans, leading to lack or inadequate loss of volatile acids, but also hydrolysis occurring during storage can lead to FFA formation [26].

The free fatty acid liberated from triglycerides in the other mixtures, such as M3 (4.89 $\pm 0.81 \%)$, M4 $(6.49 \pm 0.00 \%)$ and RSF $(6.86 \pm 0.16 \%)$ were higher as compared to $\mathrm{CB}$ $(2.72 \pm 0.65 \%), \mathrm{M} 1(3.01 \pm 0.32 \%)$ and M2 (3.47 $\pm 0.16 \%)$ (Fig. $3)$. The variation of the free fatty acid due to differences in the proportion of the mixture's component of cocoa butter and rambutan seed fat. The result showed that rambutan seed fat contains a higher proportion of oleic acid than that observed in cocoa butter. Therefore, we can exhibit that M3, M4 and RSF had the highest ratio of rambutan seed fat and free fatty acid, respectively.

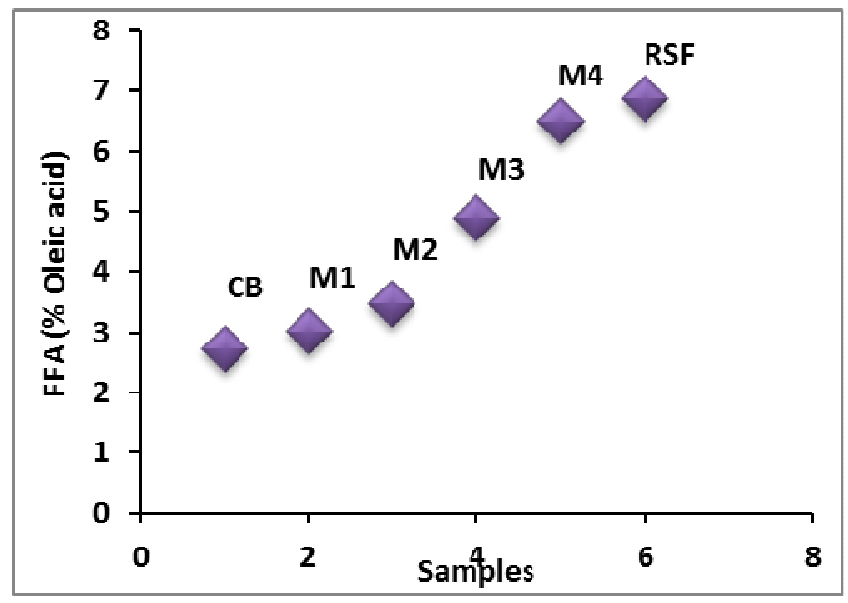

Fig. 3 Analysis of free fatty acid (FFA) of RSF and its mixture with CB

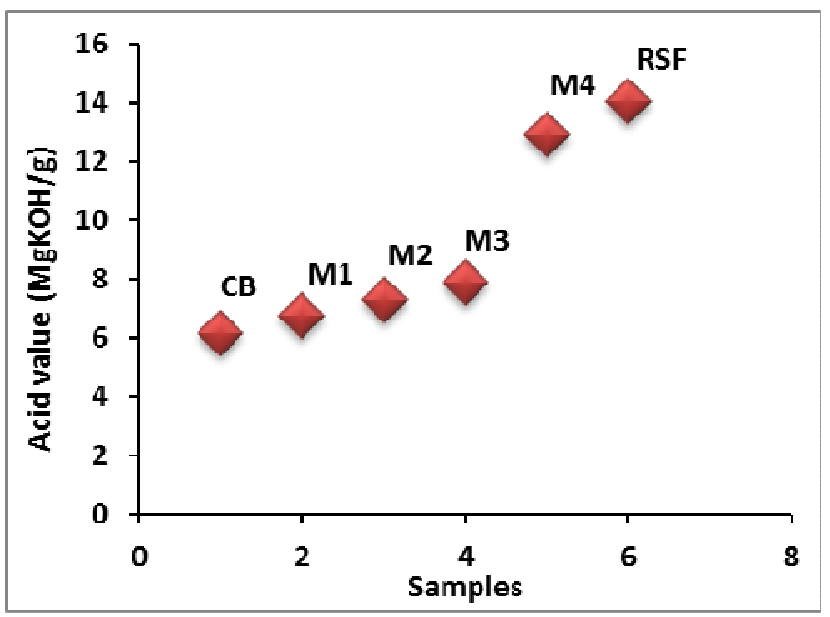

Fig. 4 Analysis of acid value (A.V) of RSF and its mixture with CB

With regard acid value (Fig. 4), high acid value was found in sample RSF $(13.66 \pm 0.23)$ and M4 (12.91 \pm 0.00$)$ followed by M3 $(9.73 \pm 1.6)$ and $\mathrm{M} 2(5.98 \pm 0.64) \mathrm{mgKOH} / \mathrm{g}$, whereas a low acid value was found in the samples CB (4.68 1.29$)$ and M1 (5.98 \pm 0.64$) \mathrm{mgKOH} / \mathrm{g}$, respectively. From our results, the proportion of monounsaturated fatty acid (MUFA) in rambutan seed fat was $(42.46 \%)$ significantly higher than found in cocoa butter $(22.44 \%)$. That can be explained the 
highest value of the acid value in rambutan seed fat in comparison with cocoa butter.

\section{CONCLUSIONS}

Our analysis on texture properties, thermal stability, and viscosity of the mixtures between fermented-roasted rambutan seed fat and cocoa butter resulted in a conclusion that the incorporation between RSF and CB may potentially be applied. The hardnesses of the mixtures were lower ranged from 11.18 to 24.77 in M3, M4 and RSF compared to 57.55 to 63.85 in $\mathrm{M} 1$ and $\mathrm{CB}$. The thermal stability of fermented-roasted RSF was lower than M1 and CB. The degradation point exhibited in M1 ranged from 344.39$521.14^{\circ} \mathrm{C}$ and $394.59-616.06$ in $\mathrm{CB}$ compared to 291.91482.83 in RSF. Effect of different temperature on the viscosity of $\mathrm{CB}$ and $\mathrm{M} 1$ shows significant differences in comparison with other mixtures. The results exhibited that CB and M1 had a lower viscosity than M2, M3, M4 and RSF with increasing temperature. From these results, it was found that it is possible to utilize rambutan seed fat as a cocoa butter replacer which allows the mixing with cocoa butter in small ratio or can also be utilized for other confectionery product in the absence of cocoa butter.

\section{ACKNOWLEDGMENT}

We extend our appreciation to the school of Industrial Technology, Department of Food Technology, University Sains Malaysia for funding the work and their keen interest in accomplishing this work.

\section{REFERENCES}

[1] Gunstone, F. D., and F. B. Padley, Lipid technologies and applications, 3rd ed., Boca Raton, FL: CRC press, 1997.

[2] Sato, K., "Crystallization behavior of fats and lipids-a review", CHEM ENG SCI, 56(7): 2255-2265, 2001.

[3] Shukla, V., and C. Akoh, "Cocoa butter, cocoa butter equivalents, and cocoa butter substitutes", Handbook of functional lipids p. 279307, 2006.

[4] Bootello, M. A., et al., "Evaluation of high oleic-high stearic sunflower hard stearins for cocoa butter equivalent formulation", FOOD CHEM, 134: 1409-1417, 2012.

[5] Issara, U., W. Zzaman, and T.A. Yang, "Review on Rambutan Seed Fat as a potential source of cocoa butter substitute in Confectionary Product", INT FOOD RES J, 21(1): 25-31, 2014.

[6] Hassan, M., J.B. Philippe, P. Alain, G. Gerard, "Production of cocoa butter equivalents from prickly-pear juice fermentation by an unsaturated fatty acid auxotroph of Cryptococcus curvatus grown in batch culture" J. PROCESS BIOCHEM, 30(7): 629-634, 1995.

[7] Zzaman, W., U. Issara, , N. F. Febrianto, and T. A., Yang, "Fatty acid composition, rheological properties and crystal formation of rambutan fat and cocoa butter" INT FOOD RES J, 21(3): 983-987, 2014.
[8] Lipp, M., E., Anklam, "Review of cocoa butter and alternative fats for use in Chocolate Part A. Compositional data" FOOM CHEM, 62:73-97, 1998

[9] Febrianto, N. A., "Effect of Fermentation and Roasting Treatment on Fat of Rambutan (Nephelium lappaceum L.) Seed and Its Potential Utilization as Confectionery Fat", M.Sc. Thesis. Universiti Sains Malaysia. Penang, Malaysia, 2013.

[10] Lannes, S.C.S., M.L., Medeiros, and L.A., Gioielli, "Physical interactions between cupuassu and cocoa fats" Grasas y Aceites, 54: 253-258, 2003.

[11] Asmaa, A. A., W. Zzaman, and A. Y. Tajul, "Effect of superheated steam cooking on fat and fatty acid composition of chicken sausage" INT FOOD RES J, 22(2): 598-605, 2015.

[12] AOAC, "Association of Official Analytical Chemists" 15th Ed.; Arlington, 15/e, Gaithersburg, 1995.

[13] Lawless, H.T. and H. C. Heymann, "Sensory evaluation of food principles and practices", 2th ed. Heidelberg: Springer-Verlag Berrlin. P. 8-75, 2010.

[14] Zzaman, W., R. Bhat, and T.A. Yang, "Effect of Superheated Steam Roasting on the Phenolic Antioxidant Properties of Cocoa Beans", J FOOD PROCESS PRES, 38 (4): p. 1932-1938, 2014.

[15] Narine, S.S., A.G. Marangoni, "Fat Crystal Networks", Marcel Dekker, New York, p. 179-255, 2005

[16] Lannes, S.C.S., M.L. Medeiros, and L.A. Gioielli, "Physical interactions between cupuassu and cocoa fats", Grasasy Aceites, 55: 115-121, 2004.

[17] Lannes, S.C.S. and L.A. Gioielli, "Misturas entre manteiga de cacau e sucedaneoscomerciais: estudo de diagramas de curvasiso-solidas e de iso-consistencia" REV SOC BRAS, 15:132-7, 1997.

[18] Zee, F., Rambutan and pili nuts: potential crops for Hawai. In: Janick, J., Simon, J.E. (Eds.), New Crops, p. 461-465. Wiley and Sons Inc., New York, 1993.

[19] Solís-Fuentes, J.A., et al., "Composition, phase behavior and thermal stability of natural edible fat from rambutan (Nephelium lappaceum L.) seed" BIORES TECHNOL, 101: 799-803, 2010.

[20] Sirisompong, W., W. Jirapakkul, and U. Klinkesorn, "Response surface optimization and characteristics of rambutan (Nephelium lappaceum L.) kernel fat by hexane extraction" LWT-FOOD SCI TECHNOL, 44: 1946-1951, 2011.

[21] Teng, Y., Y. Xu, and D. Wang, "Production and regulation of different lipase activities from Rhizopus chinensis in submerged fermentation by lipids" Jiangnan University, PR China: State Key Laboratory of Food Science and Technology. thermal treatment of refined and unrefined vegetableedible oils. Czech J. Food Sci., 28: 376-384, 2008

[22] Sudaryatiningsih, C., and Supyani, "Linoleic and linolenic acid analysis of soybean tofu with Rhizopus oryzae and Rhizopus oligosporus as coagulant” BIOSCI, 1: 110-116, 2009.

[23] Zaidul, I.S.M., N.A. Norulaini, A.K. Mohd Omar, and R.I. Smith, "Blending of suprecritical carbon dioxide (SC-CO2) extracted palm kernel oil fractions and palm oil to obtain cocoa butter replacers" J FOOD ENG, 78:1397-1409, 2007.

[24] Manaf, Y. N. A., etal., "Physico-chemical characterization of the fat from red-skin rambutan (Nephellium lappaceum L.) seed" J OLEO SCI, 62(6), 335-343, 2013.

[25] Chaiseri, S., P.S. Dimick, "Lipid and hardness characteristics of cocoa butters from different geographic regions" J AM OIL CHEM SOC, 66: 1771-1776, 1989.

[26] Rajko, V., V. Sergeja, and A. Helena, "Biochemical parameters and oxidative resistance to thermal treatment of refined and unrefined vegetableedible oils", CZECH J Food SCI, 28: 376-384, 2010. 